\title{
Crisis y refundación del mito democrático: el octubre chileno, preguntas y tensiones
}

\author{
Crisis and the refounding of the democratic myth: \\ The Chilean October, questions and tensions
}

\author{
Juan Pablo Arancibia Carrizo; Tuillang Yuing Alfaro** \\ *Escuela de Periodismo. Universidad de Santiago de Chile. \\ Proyecto Fondecyt Iniciación N¹1190173 \\ juan.arancibia.c@usach.cl \\ **Facultad de Pedagogía. Universidad Academia de Humanismo Cristiano. \\ Proyecto Fondecyt Iniciación Nº11180085 \\ tuillang.yuing@uacademia.cl
}

\begin{abstract}
Resumen
En base a una tradición teórica crítica de la democracia, el artículo ensaya una interpretación de la revuelta chilena de octubre de 2019. Se sostiene entonces que este episodio indica el agotamiento del mito en el cual, la democracia obtiene su legitimidad y perpetuación como promesa de realización de sus valores fundacionales. Con este fin se examina el contexto histórico global en el que desarrolla la transición democrática chilena, para descubrir así su estrecha vinculación con el orden diseñado por la dictadura chilena. Una serie de simbolismos articulan el orden global del mercado con el modelo social propiciado por la dictadura, pero implementado con apariencia democrática. Finalmente se revisan los elementos que permiten comprender en la revuelta de octubre los signos del colapso del «mitologema democrático» y realizar preguntas sobre los desafíos políticos que se presentan.
\end{abstract}

Palabras clave: democracia, revuelta chilena, dictadura, transición, filosofía política.

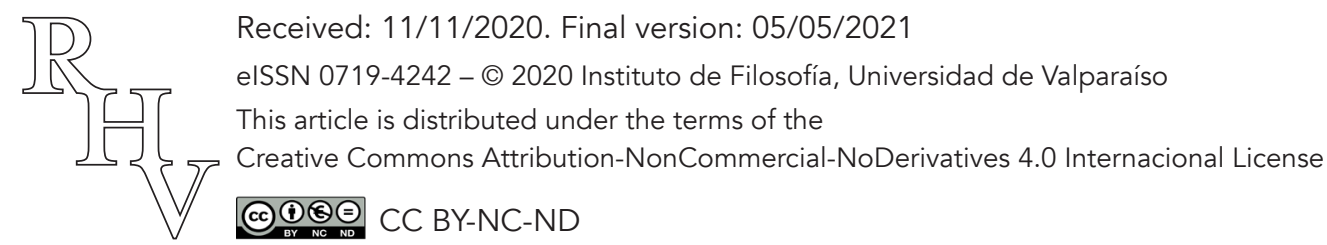




\begin{abstract}
Based on a critical theoretical tradition of democracy, the article rehearses an interpretation of the Chilean revolt of October 2019. It is argued that this episode indicates the exhaustion of the myth in which democracy obtains its legitimacy and perpetuation as a promise of the realisation of its founding values. To this end, it examines the overall historical context in which the Chilean democratic transition is taking place, thus discovering its close link to the order designed by the Chilean dictatorship. A series of symbolisms articulate the global market order with the social model favoured by the dictatorship, but implemented with a democratic appearance. Finally, the elements that allow us to understand the signs of the collapse of the 'democratic mythologem' in the October revolt are reviewed and questions are asked about the political challenges that are posed.
\end{abstract}

Keywords: democracy, Chilean revolt, dictatorship, Chilean transition, political philosophy.

\title{
1. Introducción
}

Sin duda alguna, la serie de manifestaciones ocurridas en Chile durante octubre y diciembre de 2019 tuvieron un enorme impacto en vastas áreas de la sociedad y la cultura del país. El balance de ese acontecimiento está lejos de estar resuelto y, por tanto, existen aún una serie de interrogantes cuya envergadura y profundidad compromete aspectos que no se reducen a las vicisitudes y coyunturas políticas del último tiempo. Como un acontecimiento mayor en el devenir político de Chile, el comúnmente llamado "Estallido social" de Octubre ha sido atendido por una cantidad abrumadora de análisis que articulan dimensiones y campos heterogéneos que van desde las estructuras políticas hasta los medios de comunicación, pasando por la institucionalidad económica, educativa, social y otras esferas cuyos efectos aún deben examinarse con atención.

La cuestión política, por razones obvias, toma protagonismo en estos exámenes. No obstante, los análisis - de modo general, pero de modo especial cuando aluden a este tipo de episodios - tienen un doble carácter. Por una parte, pueden hundirse en el torbellino de cuestiones circunstanciales, respondiendo e interpretando el encadenamiento de hechos y el juego de fuerzas más manifiesto, pero, por otra parte, invitan siempre a una revisión más detenida sobre estructuras, concepciones y teorizaciones donde la política es considerada desde una dimensión mayor, inscrita en preguntas y tradiciones que desbordan la contingencia.

En nuestra lectura, se ensaya un diálogo entre estos dos registros, pero a la luz de lo que en la teoría política se ha elaborado como la crítica a la democracia, vale decir, la puesta en cuestión tanto de los fundamentos de las democracias occidentales así como de sus modos de implementación práctica. De esta manera, se busca inscribir la revuelta del 
octubre chileno al interior de las coordenadas de una crisis general de la democracia en la que, desde nuestra perspectiva, cobra pertinencia y nuevos sentidos para su comprensión y lectura. Así, apelando a una mirada teórico-filosófica, se establece, de modo sugestivo, algunas tensiones y problemas que caracterizan a la democracia tanto a un nivel general, así como también en un análisis situado y específico en la historia reciente de Chile. La tesis cardinal del artículo sostiene que el octubre chileno señala el agotamiento y fractura del mito democrático, vale decir, el descrédito de su promesa y su coeficiente de perpetuación.

Este análisis se formula en cuatro momentos consecutivos pero analíticamente implicados. En primer lugar, daremos cuenta del carácter mítico que constituye la estructura misma de la democracia. En este punto revisaremos las definiciones que implican una recomposición permanente de la democracia como lugar de realización de sus valores fundacionales. En un segundo momento, pondremos el acento en el contexto histórico global en el que toma sitio la democracia chilena, incorporando en este punto las críticas que comparte junto a las democracias liberales enfrentadas al orden del mercado. Estos dos momentos sintetizan el examen de la democracia en general para, en un momento posterior, abordar la composición significante del «mitologema democrático» en el caso chileno, a través del análisis de una serie de episodios que han escenificado el tránsito de un régimen dictatorial a otro calificado como democrático. Como cuarto momento, se analizan los contenidos que manifiestan, en la revuelta de octubre, los signos de crisis y colapso del «mitologema democrático», así como también las astucias y recomposiciones del juego estratégico de fuerzas que lo integran y conforman. Finalmente, las conclusiones dan cuenta de las interrogantes que, a partir de estos análisis, se desprenden y para poder levantar algunas hipótesis sobre los desafíos que parecen avecinarse.

\section{La refundación del mito democrático}

Una amplia y variada gama de autores contemporáneos, de las más diversas corrientes (Bobbio 2003; Esposito 1996; Macpherson 2003; Touraine 2006; Mouffe 1999; Rosanvallon 2007; Ruiz 1993; Rancière 1994; Habermas 1999; Wolin 2008; Brossat 2008; Agamben 2004; Nancy 2009; Badiou 2010; Todorov 2017; Runciman 2018; Mounk 2018), han planteado durante las últimas décadas $-\mathrm{y}$ con especial insistencia, en sus más recientes publicaciones - , la problemática fragilidad y aporía de la democracia. A modo de ejemplo - en una versión extrema- Levitsky y Ziblatt han sostenido que se estaría haciendo cierto ese oscuro presagio de Larry Diamond de que la democracia está en recesión en todo el mundo, y que desde el hito de la presidencia de Donald Trump en 2016, Estados Unidos ha dejado de ser un promotor de la democracia y se ha convertido en el gobierno menos democrático en su historia $(2018,238-239)$. Asimismo, una abundante investiga- 
ción de las ciencias sociales, la sociología política, la ciencia y teoría política, indican con persistencia que la democracia atraviesa un contexto de debilitamiento, descrédito o abierta crisis de representación y participación.

Existe, entonces, suficiente evidencia - tanto en el plano teórico-analítico, como en el plano histórico de su operación efectiva- que permite dar cuenta del principio mítico de la democracia en cuanto ideal político. En efecto, la virtud y potencia, pero al mismo tiempo el problema constitutivo de la democracia, es que ella se configura a partir de una axiología política que se ejercita y pone en movimiento bajo la forma del deseo, prefigurando valores de libertad, justicia, igualdad, dignidad, incluso felicidad —en sentido aristotélico-. Parecieran estos asentarse como derechos constitutivos y valores distintivos de la democracia. Sin embargo, en torno a ello es preciso explicitar, en lo inmediato, dos aprehensiones básicas.

La primera, es que dicha axiología se comporta como pulsión y deseo constitutivo del «mitologema democrático». La democracia funda una axiología que luego traza como su propio horizonte de sentido. Al mismo tiempo, instaura su premisa que, a la vez, proyecta como promesa. Así, premisa y promesa democrática coinciden. La virtud que la fundamenta, se pone como «telos» a alcanzar (Arancibia 2011). En la afirmación y administración de dicha promesa yace todo el ejercicio y el juego del "sueño democrático". Toda la tradición democrática moderna estaría atravesada, sino constituida por dicha axiología -incluyendo la fraseología democrática con que se encubre y disimula tácticamente el «demofascismo»y las diversas tradiciones del conservadurismo de derecha antidemocrática- De modo que, en torno a dichos valores y conceptos, parece existir un consenso universal, una indistinción y consenso democrático que proclama a la democracia como un valor en sí mismo, en cuanto ella sería garante y realización civilizatoria de aquella axiología política.

Al respecto, cabe señalar que una amplia literatura convencional se limitó a identificar y circunscribir la racionalidad totalitaria a la acotada experiencia nazi-fascista, mientras otros estudios identifican ciertos principios constitutivos de lo que han denominado la «lógica totalitaria». El problema que se suscita, tal como indica Traverso (2001), es que los medios de comunicación y los productores de opinión han presentado una visión extremadamente simplificadora y descomplejizada del fascismo. De allí que, en lo que nos convoca, la sola asociación entre Estado de derecho y democracia sea insuficiente para despejar el problema, pues, en el plano analítico de la teoría política, es sabido que - tal como indica Habermas - : toda dominación política se ejerce bajo la forma del derecho $y$, por tanto, existen también ordenamientos jurídicos allí donde la violencia política no está aún domesticada por el Estado de derecho (Habermas 1999, 247). De este modo, la relación entre fascismo y democracia se torna algo más intrincada y compleja que una mera declaración y existencia formal del derecho. 
La segunda aprehensión concierne precisamente a esto último: una vez que la democracia parece fundirse y confundirse con los valores que propugna, entonces ella se sacraliza como un valor y un fin en sí, obliterando o disolviendo aquella concepción que la piensa y sitúa como medio posible, como instrumento, vía o forma —de Constitución y de Gobierno- para alcanzar, producir o realizar dicha axiología. A partir de ello -y a la luz de la evidencia histórica y teórica-, surge un problema decisivo, cual es: que la democracia no necesariamente es el "único camino adecuado", imaginable o concebible para realizar dicha axiología. En estricto rigor, la muestra mayor de aquello es que en su operación efectiva, material, práctica e histórica, la democracia no sólo está y ha estado lejísimo de realizar o alcanzar dichos valores, sino que en su propia racionalidad, ella misma se torna portadora y ejecutora de su denegación.

De este modo, existe abundante evidencia histórica, económica, social y política para que, desde una perspectiva razonable, se cuestione e interrogue críticamente las premisas y los vectores de desarrollo democrático. Primero, porque la democracia no es la única imaginación política o el único periplo histórico y mecanismo jurídico-político que habría que recorrer para alcanzar dichos valores. Segundo, porque existe cuantiosa y dramática evidencia de que la democracia no ha alcanzado dicha axiología - y que únicamente se ha limitado a un régimen de administración de una eterna promesa incumplida- Tercero, porque su pragmática política la distancia, en los hechos, de aquellos valores que la fundamentan, evidenciando que sistemáticamente más bien administra su retraso y disimula su denegación, y así; cuarto, cabría interrogar acuciosamente el carácter y la esencia de dicha axiología política o, si se quiere, preguntar por cuáles serían aquellas premisas y concepciones de libertad, de justicia, de igualdad, de dignidad, de felicidad que dice proclamar y promover la democracia liberal. Aquella pregunta se torna particularmente relevante en un tiempo histórico en que se instaura una supremacía económica que condena no sólo a la actividad política, sino a toda dimensión de la vida a ser subsumida a la axiomática del capital. Las palabras de Nancy son iluminadoras al respecto:

Desde entonces, el vínculo económico, la operación tecnológica y la fusión política representan o más bien presentan, exponen y realizan necesariamente por sí mismos esta esencia. Allí está ella puesta en obra, allí se convierte en su propia obra. Es lo que hemos llamado «totalitarismo», y que, tal vez, sería mejor llamar «inmanentismo», si no es necesario reservar esta designación a ciertos tipos de sociedades o regímenes, en vez de ver en ella, por una vez, el horizonte general de nuestro tiempo, que engloba también las democracias y sus frágiles parapetos jurídicos. (Nancy 2001, 16)

Como bien se sabe, ha sido toda una tradición del pensamiento de la modernidad occidental la que ha macerado y consagrado ciertas concepciones de aquella axiología, dotándola de contenido a la hora de diseñar un orden social y político. En efecto, el desarrollo histórico de la democracia ha permitido a la teoría política distinguir varios modelos, ti- 
pos e intensidades democráticas (Habermas 1999; Macpherson 2003; Rosanvallon 2009), y al mismo tiempo precisar y estabilizar los fundamentos filosóficos, políticos y jurídicos que la definen. Así, pueden señalarse al menos las siguientes propuestas: a) la democracia es un conjunto de reglas procesales para la toma de decisiones colectivas adoptadas con la más amplia participación posible de los ciudadanos; b) la democracia es un punto de articulación intermedia entre Derecho y Poder, donde el estado de derecho democrático legitima, modera y regula el poder; c) el sujeto de esa regulación es la ciudadanía (Bobbio 2003, 15-21). Lo que cabría interrogar - y a esta altura se torna un imperativo para el pensamiento contemporáneo-, es precisamente la sustancia, la potencia, el espesor y densidad que comportan aquellas ideas y definiciones. De esta misma problemática se desprende una derivada: si es que, auscultada la sustancia histórica de dichos conceptos, ellos se prestan a alguna realización histórica posible o se trataría de una axiología metafísica que estaría precisamente destinada a constituir el «mitologema democrático» como forma histórica de concebir y realizar el ser-en-común (Arancibia 2010).

Otro elemento significativo consiste en el hecho de que la democracia no sólo debe administrar la promesa incumplida, sino que debe administrar también su falta. Así como el dilema ético que concierne a los individuos, tanto en la ética teleológica como en la deontológica, opone y examina el modo en que los hombres «deben actuar» con el modo en que «efectivamente actúan»; así como se confronta el modo en que los hombres «deben ser», con como «efectivamente son». Pues bien, la democracia en cuanto se constituye en una axiología política, ella está forzada y exigida permanentemente a explicar y justificar la brecha ética que distancia - y por cierto deniega - aquello que la democracia «debiera ser» y lo que ella «efectivamente es», vale decir, la diferencia entre aquello que la democracia «debiera hacer» y lo que ella «efectivamente hace». Se trata, entonces, de una desviación que parece inherente a su régimen y que Todorov ilustra de la siguiente manera:

Pues el poder político no puede, o no quiere, limitar el poder económico de las multinacionales, los bancos y agencias de calificación. El rasgo que todas estas desviaciones comparten es que proceden no de ataques externos, sino de principios internos a la propia democracia. (Todorov 2017, 85)

De esta forma, el discurso democrático se ve permanentemente interpelado a responder e intentar explicar o justificar dicho abismo y negación. De acuerdo a la axiomática de la promesa del «mitologema democrático», la democracia no debiera asesinar, sin embargo, en los hechos, asesina; no debiera torturar, en los hechos, tortura, así en más, no debiera ser corrupta, en los hechos, lo es; no debiera ser injusta, pero, de hecho, lo es. Esta contrariedad y denegación es lo que Sheldon Wolin (2008) ha llamado la "inversión democrática". Esta inadecuación democrática o "inversión democrática" acontece, explica Wolin, cuando un sistema, como una democracia, produce un número de acciones significativas que suelen asociarse con sus antítesis: por ejemplo, cuando el jefe electo del ejecutivo tiene el poder de encarcelar a un acusado sin garantías procesales, cuando 
sanciona el uso de la tortura mientras que instruye a la nación acerca de la santidad del Estado de derecho. "Este nuevo sistema, el totalitarismo invertido, profesa ser lo opuesto de lo que es en realidad. Niega su verdadera identidad, en la esperanza de que sus desviaciones sean normalizadas como «cambios»" (Wolin 2008, 83).

De este modo, la habilidad de la «jerga democrática» no sólo debe consistir en renovar su promesa y axiología, justificando y administrando su incumplimiento, sino que además - lo que no deja de ser un aspecto fascinante de la «mitopoiesis democrática»- es que resulta perfectamente capaz también de administrar su falta, es decir, de incurrir y acometer sistemáticamente todo aquel conjunto de acciones y prácticas que, supuestamente, ella no acomete y de las cuales, más radicalmente, ella misma como régimen político nos ofrecía su salvífica protección -injusticia, desigualdad, violación de derechos fundamentales, corrupción y otros-.

Para justificar esa distancia y denegación axiológica, y así renovar el circuito de su promesa garante de derechos inviolables — que luego se vuelven a violar-, la democracia se sirve de una mecánica tecnología política de "impunidad, reparación y reconciliación". Estos dispositivos jurídico-políticos adquieren un carácter universal y poseen una extraordinaria potencia simbólica, donde uno de sus actantes fundamentales es la retórica de la «reconciliación». Así, la «reconciliación» constituye un dispositivo simbólico-político regulador y restaurador de la propia excepcionalidad democrática (Arancibia 2006). De este modo, la democracia opera su mecanismo jurídico redentor de permanente renovación de la promesa, equiparable al emblemático "para que nunca más". Sin embargo, aquello que se sentencia "nunca más", no hace más que repetirse y reanudarse, una y otra vez.

Asimismo, no deja de ser interesante el circuito axiomático y repetitivo de la serie de gobiernos democráticos en que altos personeros y autoridades incurren en diversos hechos dolosos - el abanico es amplio y frecuente- y, en defensa de los valores democráticos, son sometidos a procesos judiciales y reemplazados por nuevas autoridades democráticas que, a su vez, nuevamente serán acusados y sometidos a procesos judiciales para, nuevamente, ser reemplazados por insignes paladines de la democracia, quienes, por su parte, serán acusados de cometer actos dolosos impropios de la democracia.

La relación hoy estrecha entre corrupción y mecanismos democráticos ha sido generosamente analizada. Contra las tesis que, hace algunas décadas, señalaban a la corrupción como un fallo o avería de las democracias "subdesarrolladas" (Linz 1988; Anderson y Tverdova 2003), paulatinamente hoy se advierte la transversalidad de esta componente en la estructura misma de la institucionalidad (Covarrubias 2005; Jaramillo Gabanzo 2010). La iteración estructural de este mecanismo de juicio político de la democracia ideal contra la democracia corrupta opera como tecnología jurídico-política de expiación del pecado original y su eterna redención, pues es la misma judicatura política de la institucionalidad democrática quien acomete dichos flagelos y delitos, para que luego sea la misma judi- 
catura e institucionalidad la que redima sus valores y preceptos, en nombre de los cuales asumen nuevos insignes demócratas, los que en un tiempo breve serán eventualmente desbancados por corruptos y nuevamente reemplazados por otros. En definitiva, se trata de una narrativa que se ha hecho moneda corriente de la escena política y su exposición mediática.

La acuciosidad de dichos enjuiciamientos dependerá de múltiples factores y condiciones específicas de cada democracia y la correlación de fuerzas que litiguen en su interior (Covarrubias 2005). Hay casos en que esta dinámica se practica con particular frecuencia, agilidad y devoción — considérese los escándalos de las últimas décadas en México y Colombia, entre otros-, en otras democracias los casos de corrupción y criminalidad se llevan con cierto talento en el arte del disimulo y el recato, de modo que se condonan deudas y se dictan clases de ética a los condenados — como en los desfalcos concertados por el empresariado y las fuerzas armadas en Chile. No deja de resultar una ironía de la democracia que la ética sea entendida y asumida como una condena. De este modo, existen próceres democráticos, autoridades políticas y el alto mando de fuerzas armadas y policías que han sido involucrados en escandalosos casos de crímenes políticos y corrupción, generalmente asociados a la incestuosa relación entre dinero y política, pero que hasta el día de hoy gozan de una poderosa panoplia que les resguarda y, por cierto, preserva en sus cargos y privilegios (Jaramillo Gabanzo 2010).

Entonces el juego axiomático del «mitologema democrático» no consiste en cumplir su promesa, ni siquiera en proponérselo, sino que su potencia consiste en la reanudación del mito, en su iteración y afirmación. Así, la democracia sólo necesita que su promesa sea creída en cuanto tal, acreditada como promesa. A esta lógica propia de la gubernamentalidad neoliberal, Michel Foucault la denominó «normalización», en cuanto no requería ni se planteaba eliminar o superar ciertos "males" de la sociedad, sino que sólo demanda conservarlos bajo ciertos índices de normalidad. De este modo, desde esta racionalidad de gobierno, no se precisa verdaderamente eliminar la corrupción, sino sólo mantenerla controlada, de modo que los "males y vicios" de un régimen de orden no alcancen índices mórbidos. Estos dispositivos de normalización operan bajo la lógica de lo que Foucault denomina «liberógenos», entendidos como aquellos mecanismos productores de libertad, al tiempo que ejercen su control, constricción y privación. (Foucault 2006).

Teniendo este análisis a la base, es posible sospechar que lo que se fractura y resulta craquelado el 18 de octubre de 2019 es, precisamente, el mito democrático, la promesa democrática que se había instaurado desde el plebiscito de 1988 con el lema de "la alegría ya viene" y consagrado institucionalmente el 11 de marzo de 1990. Ese ciclo mítico-político de treinta años se desploma, en efecto, en reclamación de aquella promesa, de una alegría que nunca llegó, o no al menos a quienes se les hizo la promesa. Una extensa bibliografía ha examinado las particularidades de la llamada transición chilena a la de- 
mocracia. En estos análisis se comparte un diagnóstico que mezcla aspectos político-jurídicos con cuestiones económicas y de desarrollo. (Moulian 1997; Lechner 1988; Mayol 2012; Atria 2013).

Con todo, la recomposición del mito democrático ha operado así en su plenitud. En efecto, la teoría subentiende que la democracia es dinámica, plural y transformadora, mientras que el despotismo es estático y monolítico. La diferencia subyace en el hecho de que la democracia es el régimen de reconocimiento y expansión del derecho, mientras que el despotismo es la negación y constricción de los derechos (Lefort 1990, 15). Los principios filosóficos y jurídicos de la democracia enseñan que éste es el sistema político que se define por su carácter agonístico y adversativo, donde el juego político - con arreglo a derecho-, consiste necesariamente en el reconocimiento y ejercicio de su condición litigante, plural y diferencial (Mouffe 1999). De allí que la democracia sea entendida como el régimen de gobierno que resguarda, practica y promueve la libertad y los derechos de todos sus miembros. Por esta razón, como es propio del mito que opera por repetición y necesita de una ritualidad que le restaure y reactive, ese mito político se vuelve a refundar.

La noche del 15 de noviembre de 2019 la casta gobernante debatió si volver a sacar a los militares, - esta vez con total garantía de impunidad para hacer sus "labores"-, o generar un acuerdo macropolítico de las élites que pudieran hacer concesiones significativas para salvar en lo sustantivo aquello que estaba en riesgo de perderse completamente ${ }^{1}$. Aquella noche, ya de madrugada, los agentes de la clase política y de las élites celebraron y se abrazaron, festinando una épica jornada. ¿Qué era tan importante que justificaba tal algarabía y celebración? No era otra cosa que haber acordado un mecanismo simbólico-político que ratifica la restauración del mito, una nueva promesa, una nueva esperanza para los gobernados, un nuevo aplazamiento de la crisis y el desplome, que por esos días se tornaba inminente y casi inexorable. Esta restauración del mito aseguraría un nuevo período de gobernabilidad y confirmación del orden (Arancibia 2016a).

El mito por cierto ya se reinstauró, la promesa está nuevamente trabajando. Todo un amplio y complejo tramado logístico de mecanismos, recursos y enunciados estéticos, políticos y mediáticos, ya han sido movilizados para la refundación del «mitologema democrático» (Arancibia 2016b). Desde esta perspectiva, realista y apesadumbrada por cierto, una cosa resulta segura y puede ya ser sabida por anticipado. Ejecutoriado el mitologema, prevalecerá la estructura orgánica fundamental de este orden social, económico y político: seguirá existiendo miseria, explotación de las trabajadoras y trabajadores, injusticias, abusos, desigualdades, y la vida de la gran mayoría de la población seguirá siendo sistemáticamente ultrajada. Seguirá habiendo pobres, muchos pobres, siempre más allá de "lo

\footnotetext{
${ }^{1}$ Acuerdo por la Paz Social y la Nueva Constitución (15 de noviembre de 2019). Santiago, Chile. Recuperado de: https:/www.senado.cl/senado/site/mm/20191114/asocfile/20191114134609/pdf_acuerdo_por_la_ paz_social_y_la_nueva_constitucion.pdf
}

Revista de Humanidades de Valparaíso, 2021, No 17, 91-113

(c) $(1) \Theta(\Theta)$ CC BY-NC-ND 
aceptable y lo deseable", seguirán enriqueciéndose los ricos, cada vez más ricos, siempre más allá de "lo aceptable y lo deseable". Se reanudarán nuevos casos de desfalcos y corrupción —sólo aquellos de los que logremos enterarnos-, seguirán los privilegios, los abusos, las castas económicas y políticas, en suma, continuará la criminalidad del orden.

Tras la refundación del mito, nada sustantivo habrá cambiado, pues el mito tiene por carácter el sostenimiento de un esquema, su resguardo y conservación. La democracia como mito no está destinada a transformar o crear un mundo y una sociedad nueva y distinta, sino que está axiomáticamente destinada a legitimar y conservar el orden que ya existe.

Ahora bien, estas cualidades y características de la democracia se han acentuado de modo especial en el horizonte de las democracias liberales asociadas al paisaje político-global que se fue diagramando y ganando terreno, casi sin resistencia, al menos desde fines de la década del ochenta. Esto aplica en especial para el contrato de sentido que se fue estableciendo entre democracia y neoliberalismo en el paisaje denominado global o de "Nuevo Orden Mundial". La caída del Muro de Berlín y el derrumbe de la Unión Soviética inician un panorama político que no ofrece lugar a la ambigüedad ni al conflicto, promoviendo que un modelo de desarrollo unívoco se instale hegemónicamente (Abélès 2008; Hardt y Negri 2002). Se vislumbra así un solo mundo donde antes se percibía una tensión. El mundo político parece tener un triunfador que habría hecho del neoliberalismo económico su opción predilecta. Sin embargo, dicha victoria da paso, casi de forma inmediata, a una suerte de invasión del escepticismo en la política. Los ideales y las ideologías hacen su retiro frente a altísimas dosis de desidia y desilusión, y frente a una política que se muestra cada vez más inútil y lejana (Macpherson 2003). Deberemos dar cuenta más precisa de este punto.

\section{Las promesas fallidas del orden}

Tras el derrumbe del bloque soviético y la consolidación del modelo capitalista liderado por Estados Unidos, las democracias occidentales parecen establecer un acuerdo específico con la esfera del mercado, subordinándose a una racionalidad económica que las limita en su campo de acción y desempeño. Se asiste a una distribución de las fuerzas que, pese a un cierto coeficiente de virtualidad, se presenta como una conformación política-económica indiscutible, un fin que se considera valioso, logrado y que no admite cuestionamiento. Entre muchos otros ha sido Pierre Rosanvallon (2011) quien advierte de un despliegue inversamente proporcional de las democracias liberales según el cual, a mayor sofisticación y sistematización de los mecanismos democráticos - periodicidad de elecciones, instancias de supervisión, registro y seguimientos de los procesos electorales, espacios de propaganda y otros-, le corresponde simultáneamente, de parte de la sociedad civil, una percepción de deslegitimación e inoperancia. En otras palabras, mientras más la democracia avanza como mecanismo institucional, menor es su valoración como 
agente real de transformación política. A la base estaría el «mitologema democrático» y las promesas fundacionales que habrían inspirado la conformación de los mecanismos representativos — como podrían ser la igualdad, la dignidad y la justicia-, que la puesta en forma efectiva de estos regímenes no habría podido realizar sino tan solo poner como una meta siempre desplazada. En palabras de Rosanvallon: "La ciudadanía política avanza a la par que retrocede la ciudadanía social. Esa fractura de la democracia es el hecho más importante de nuestro tiempo, portador de las más terribles amenazas. De continuar así, sería el propio régimen democrático el que acabaría tambaleándose (Rosanvallon 2011, 11) (...). Y más adelante agrega: "Se trata de una contradicción que es fundamental investigar. Contradicción que es la réplica a la brecha que se está ahondando entre el progreso de la democracia y el retroceso de la democracia-sociedad" (Rosanvallon 2011, 13).

El diagnóstico de Rosanvallon permite constatar algunas fracturas basales que son compartidas por buena parte de las democracias representativas actuales: en la misma medida que la democracia se consolida como régimen, la ciudadanía tiene una percepción crítica que es portadora cada vez más de un descontento general que es transversal al cuerpo social. Se trata de un descontento que dirige su ofensiva ante la incapacidad estructural del sistema político por llevar a cabo cambios de envergadura que redirijan los cursos de acción colectiva en los que se ve sumida la ciudadanía. Esto ha llevado a algunos autores (Bringel y Pleyers 2017) a hablar de la indignación como "un estado de ánimo" que puede expresarse de maneras diferentes que van desde la anomia y la apatía a la participación, hasta el reclamo permanente a la clase política dada su incompetencia para enfrentar las sucesivas crisis. Esto desemboca en un debilitamiento de la democracia como forma de sociedad y en una desintegración del sustrato "pueblo" que funciona cada vez menos como un cuerpo social activo y reducido, al contrario, a una mera instancia de validación. Desde luego, el caso chileno no está ajeno a este debilitamiento y, es más, acusa una serie de problemáticas que se suman como factores que deslegitiman el carácter democrático que pudiese haber en la institucionalidad política tal y como ha sido implementada desde al menos 1990.

\section{La transición como afirmación de un orden inmutable}

Vale la pena ensayar, entonces, una retrospectiva que analice el "fin" de la dictadura (1988-89) en relación con el escenario global en el que tuvo lugar. Como ya hemos adelantado, se trata de aquel momento que muchos autores han identificado con la caída del muro, el fin de las ideologías y la instalación de una escenografía única con decorados simbólicos incuestionables. Una escena que llevó a algunos por ejemplo a decretar que "el modelo anterior de bloques antagónicos había terminado" (Cuellar, en Thayer 1996, 172). Varios autores advirtieron en su momento esta superposición entre el diseño de la transición llevada a cabo en Chile y, el esquema de fuerzas y la diagramación política a nivel global. Las palabras de Thayer son ilustrativas a este respecto: 
El mundo, desde la transición, es uno en la variedad de las fuerzas que lo configuran. Nada acontece fuera de la economía global y el orden transcultural que le acompaña. Uno, diverso y disperso, irregular e inestable si enfocamos el soporte simbólico que lo conforma (...) El mundo ya está. Y dentro de él, lo posible, lo composible y lo incomposible. $(1996,171)$

En Chile, la transición funcionó como el dispositivo conceptual que fundamentó la consolidación de este paisaje. En efecto, la transición fue la excusa y el motivo para aceptar sin cuestionamiento ni crítica la implementación de una democracia liberal adaptada a las dinámicas y reglas del mercado. Como varios autores han señalado, desde ese momento tuvo lugar la instalación de una forma de capitalismo que fagocita $-\mathrm{y}$ hasta produce- sus propias diferencias. Se asiste así a la conformación de un modo singular de capitalismo que apuesta a neutralizar todo cambio en lo que pueda tener de heterogeneidad radical, indomable o incalculable. Ahora bien, la particularidad del caso chileno no escapó a esta racionalidad sino, más bien, lo que la puesta en forma de la democracia transicional — con el maquillaje colaborativo de la Concertación de Partidos por la Democracia- consolidó de manera programática, fue precisamente ese orden que doméstica, apacigua y aletarga toda transformación. Las palabras del ex-ministro de Hacienda de la dictadura, Rolf Lüders, en 2005, son elocuentes: "La Concertación ha administrado mejor el modelo que la derecha (...) al abrazar el modelo pudo sustentarlo sin mayores reacciones sociales contrarias" (citado en Waissblutth 2010, 33).

Desde esa mirada, Chile se había convertido en un caso ejemplar para cantar las victorias del modelo hegemónico. En efecto, esta incapacidad del aparato político para implementar transformaciones profundas era celebrado y alabado como signo de estabilidad, vale decir, como un candado que garantizaba el crecimiento y el despliegue de la macroeconomía y del mercado sin rendir cuentas ni confesar sus ambiciones políticas de fondo. Al respecto, es interesante la reflexión de Salazar y Pinto (1999), quienes señalan que la estabilidad que galardona la institucionalidad chilena no equivale a eficiencia ni, por tanto, supone la legitimidad que otorgan tanto la confianza en las instituciones como "las formas en que se resolvieron los acontecimientos claves que dividieron históricamente a la sociedad" (Salazar y Pinto 1999, 15). Muy por el contrario, los historiadores cuestionan la estabilidad como valor en sí, ya que no indica más que la durabilidad de un sistema que se ha encargado, de forma persistente y continua, de ir enterrando la ilegitimidad de su mismo proceder, sustituyéndola por un discurso que haga racionalmente justificable la permanencia.

De esta manera, la estabilidad no es sino el signo de una sociedad civil disciplinada, canalizada, dócil a los marcos en que se ha establecido su participación, en una palabra: gobernable. La gobernabilidad es así también el signo de una ciudadanía en la que este modelo ejemplar no es jamás cuestionado. En suma, lo que se privilegia parece ser el modo en que la democracia se acopla al modelo liberal consolidado. La cuestión de su 
legitimidad y de su potencia, para cumplir sus promesas fundacionales, queda siempre desplazada o llevada a un rol ornamental. En el caso chileno, conviene tomar noticia de cierta ritualidad que busca escenificar el simbolismo democrático al mismo tiempo que lo reduce y lo clausura en lo que pueda tener de transformador. El examen de Moulian parece confirmar estas sospechas:

Esta sociedad, el Chile Actual, se concibe como un gigantesco mercado donde la integración social se realiza en el nivel de los intercambios más que en el nivel de lo político. Esto es, no se realiza a través de la ciudadanía convencional, de la participación, de la adhesión a ideologías. La figura del hombre político, orientado hacia la vida pública, es reemplazada por la figura dominante del individuo burgués (...). (Moulian 1997, 121)

\section{El «mitologema democrático» chileno.}

Resulta interesante observar, entonces, cómo en Chile se ha construido un orden político a partir de cierta ritualidad simbólica. Cuatro escenografías o imágenes podrían ser contrapuestas y examinadas con relación a los contextos y a las transformaciones históricas que le dieron lugar.

La primera imagen ritual es la del discurso de Chacarillas donde, acompañado de 77 "emblemáticos jóvenes chilenos", el dictador Augusto Pinochet traza un programa e itinerario de legitimación de la dictadura y que se promueve como la "nueva institucionalidad en Chile" (Pinochet 1977). Es de destacar que algunos de estos insignes jóvenes fueron férreos militantes y defensores de la dictadura, para luego ocupar cargos y roles decisivos en la estructura democrática establecida a partir de 1989.

La segunda imagen ritual, es la del triunfo del No en octubre de 1988 con la instauración de la gran promesa: "la alegría ya viene" y el icónico abrazo de ciudadanos con las fuerzas de Carabineros. Ese abrazo reconciliador venía a testimoniar la genuina esperanza de que el régimen de división y represión habría terminado. Ese abrazo venía también a simbolizar el mentado "Para que nunca más en Chile". Por cierto, esa alegría y esa reconciliación, de acuerdo con muchas interpretaciones, nunca llegaron. Y la promesa de ya "nunca más", fue violenta y dramáticamente desmentida (Moulian 1997).

La tercera imagen ritual, es la de marzo de 1990, cuando Gabriel Valdés traspasa la banda presidencial del dictador saliente al nuevo mandatario, Patricio Aylwin. Esa imagen marca el hito jurídico crucial del término de la dictadura y el inicio de la democracia. Para luego administrar el «mitologema democrático», esa imagen fue resignificada y presentada como el inicio de la transición a la democracia. Finalmente, se trató de una eterna transición cuya elasticidad, por un lado, señalaba que no vivíamos en una democracia plena pero, por otro lado, permitía alimentar la esperanza de poder en algún momento 
conquistarla. Aquella transición duró treinta años y no han faltado los analistas - especialistas en transición- que han declarado, una vez más, el fin de la transición con ocasión del plebiscito de octubre de 2020.

La cuarta imagen ritual es la de marzo de 2020, es decir, 30 años más tarde, cuando el Presidente de la República, Sebastián Piñera, acompañado del Ministro del Interior, Andrés Chadwick — uno de los "elegidos" para el evento de Chacarillas-, del Ministro de Justicia, Hernán Larraín y del Ministro de Defensa, Alberto Espina, afinan los detalles para la implementación del estado de excepción decretado por razones de la pandemia del covid-19. Cuatro consabidos otrora jóvenes pinochetistas, insignes militantes comprometidos con la defensa y proyección de la dictadura, tomando en sus manos ahora la decisión de decretar la suspensión del orden democrático o, si se quiere, de manifestar su vínculo estrecho con la excepcionalidad dictatorial (Agamben 2004; Arancibia y Yuing 2019).

Estas imágenes, analizadas con detención, marcan ciertos hitos del proceso de construcción del mito democrático, particularmente, con el contenido mítico de la transitología chilena a la democracia, cual es: "la dictadura terminó". Resulta interesante analizar, entonces, la inquietante condición indiciaria que constituye al mito democrático. Adviértase la estrecha colindancia entre dictadura y democracia. Basta un conjunto de cambios cosméticos institucionales para que, aquello que se denominaba dictadura, ejecutado el rito, un instante más tarde, pase a denominarse democracia (Arancibia 2018). Aquella configuración de poder que hace tan solo unos años, unos meses o semanas llamábamos dictadura y nos amenazaba, ahora, mediante el conjuro mítico-político, pasa a llamarse democracia, la que supuestamente ya no nos amenaza, sino que nos ampara y resguarda. Este juego ritual de la política resulta particularmente interesante porque es precisamente aquella ritualidad la que va construyendo y asentando el mito político de la democracia.

De la dictadura prevaleció su obra, su Constitución, su economía, sus instituciones, sus partidos, sus líderes, y hasta el tirano mismo y sus fuerzas sociales de apoyo. En lo sustantivo, toda la base e infraestructura jurídico-política y económica de la dictadura se preservó intacta hasta el mismo 18 de octubre de 2019. Treinta años después de que se suponía la dictadura había terminado. El mito había funcionado. Por cierto, la dictadura terminó. Lo que acontece desde marzo de 1990 se denomina democracia, y durante treinta años ha administrado, profundizado y agudizado las violencias e injusticias que se instauraron con el golpe de Estado de 1973.

De allí que esta iconografía de la ritualidad transitológica chilena torne interesante aquello que podemos llamar el «hiato democrático», precisamente como aquella articulación que distingue, que modula una separación, una escansión de aquello con lo cual se encuentra constitutivamente unida, ligada, anclada: la dictadura. Este «hiato democrático» que escande entre dictadura y democracia, también permite ver su elisión, es decir, su juntura, el estrecho vínculo que les compromete. Dicho claramente: la actual democracia 
chilena, nace configurada y definida desde la dictadura. El «hiato democrático» intenta distinguir y separar aquello de lo que la democracia está orgánica y estructuralmente unida.

Este «hiato democrático» es lo que podemos llamar «la condición indiciaria de la democracia $\rangle^{2}$. La condición indiciaria de la democracia chilena implica la preservación y el compromiso orgánico con la transformación histórica acontecida y acometida entre el 11 de septiembre de 1973 y el 11 de marzo de 1990. El «hiato democrático» implica la condición indiciaria de una democracia que no consigue diferenciarse ni despegarse de su referente fundacional que le constituye. En efecto, si bien, ya Tocqueville (1984, 264-277) advertía de la eventual y riesgosa vecindad que habría entre democracia y absolutismo, la teoría democrática contemporánea se habría ocupado de fortalecer y amurallar esta diferencia (Traverso 2001, 15-44). En ese empeño, también Hannah Arendt (1998) destinó un acucioso y emblemático trabajo a describir y sistematizar los principios del totalitarismo. Atendiendo a estas claves no es antojadizo afirmar que, en Chile, se vive en una sociedad todavía configurada y estructurada por el golpe de Estado de 1973. Ese golpe de Estado opera como un crimen fundacional y que se ha proyectado ya por casi cincuenta años.

\section{Octubre 2019 como signo de agotamiento.}

Hasta antes de la revuelta de octubre la tendenciosa opinión pública global señalaba a Chile como un país ejemplo de estabilidad, crecimiento y en el que sus habitantes gozaban de los beneficios de un desarrollo económico modelo en la región. Esta calificación se amparaba en el paisaje político global al que aludíamos en los apartados anteriores, según el cual el neo-liberalismo constituía la matriz de referencia. En efecto, a la luz de esta perspectiva, la democracia chilena era enarbolada como ejemplo de desarrollo regional, como aquel país que había hecho bien las cosas y establecido un crecimiento con cifras pujantes. Ciertamente, la crítica al modelo neoliberal implementado en Chile había ya acumulado adeptos y afinado sus argumentos, pero ello no se había traducido en una revuelta mayoritaria y reconocida desde todos los sectores. La imagen de un país de oportunidades se había mantenido incólume. No obstante, en un par de días esa imagen se vino abajo y los fantasmas más oscuros de su pasado -el de la dictadura pinochetista-, se hicieron inmediatamente presentes en imágenes de violencia y agitación verdaderamente estremecedoras (Ramírez, Yañez y Salinas 2019).

Desde luego, esta sacudida no obedecía únicamente al alza del pasaje del metro-tren sino que acusaba una trama mucho más compleja que requiere destacar algunos factores para intentar, al menos, atisbar su comprensión. Las metáforas de ese momento eran elocuentes: el alza del metro como la "punta del iceberg" del descontento; la consigna "no

\footnotetext{
${ }^{2}$ Usamos para ello la noción triádica del signo, propuesta por Ch. S. Peirce, precisamente para señalar el carácter de contigüidad y adyacencia entre dictadura y democracia. (Eco 2000).
} 
son 30 pesos, son 30 años", eran formulas indicativas de un malestar general con el modelo de desarrollo y gestión que rápidamente hizo sentido en todas las ciudades de Chile $\mathrm{y}$ en la sociedad en general. Las causas de este malestar colectivo son innumerables y, por cierto, habían sido administradas con comodidad por todos los gobiernos de turno desde la salida de Pinochet: sistema de pensiones que condena a la pobreza, precarización laboral disfrazada como flexibilidad, el endeudamiento vitalicio para enfrentar cuestiones tan diversas como la adquisición de bienes hasta la vivienda, pasando por la privatización de derechos básicos como la salud y la educación. Súmese a lo anterior una permanente percepción de injusticia ante los robos y delitos económicos cometidos por el empresariado más poderoso y la elite política, además de un nepotismo permanente en la asignación de cargos políticos. A ello se agregaba la consciencia -cada vez más manifiesta- de los impactos del extractivismo y el castigo medioambiental. Todos estos elementos explicitados ya sin hipocresía en el segundo gobierno de Sebastián Piñera confirmaron la sensación de que la democracia chilena es meramente formal -la abstención electoral había llegado a niveles irrisorios-. Muy por el contrario, estos factores ampliaron la percepción compartida de que mientras más mecanismos de "participación" democrática se implementan, más se consolidaba un sistema que abandona y agobia la vida diaria de las personas. No obstante, durante los primeros días de la revuelta, apelando a la inseguridad y al temor más primitivo, el descontento social y la demanda política concreta fueron permanentemente ocultados y negados por la información de los medios (Arancibia y Yuing, 2019), subordinando aquellas demandas específicas que están a la base del estallido político a la cuestión de la seguridad y el estado de emergencia. Se trataba de negarse al diálogo en función de la emergencia e inmediatez de re-establecer el orden, vale decir, en función de la represión.

Lo anterior es parte del deficiente manejo político del gobierno. Al momento de la crisis se percibe un perfil de autoridades al parecer poco familiarizadas con la negociación y la sensibilidad política. Desde su lenguaje, la táctica se basa en una dicotomía muy simple: o la ciudadanía es dócil o se reprime. O la adhesión incondicional o la fuerza. Salta entonces a la vista la torpeza del panel de expertos -sobre todo de economistas- que participaban de los equipos de gobierno. Acostumbrados a la lógica empresarial según la cual basta con despedir al funcionario que no simpatiza con su lineamiento corporativo, las autoridades respondieron a la demanda social ya sea con autoritarismo "experto", así como con indiferencia, pero también con burla y hasta ironía. Sin embargo, como a la ciudadanía no se le puede despedir, cuando esta demanda se fue transformando en protesta, la única respuesta viable fue el despliegue militar y de las fuerzas de orden. Esta inoperancia ya se insinuaba con claridad en la medida de sitiar con grupos de Fuerzas Especiales el Instituto Nacional, colegio secundario símbolo de la tradición republicana chilena, cuyos estudiantes habían sistematizado sus protestas desde hacía ya algunos meses. La incapacidad de negociación o convencimiento ante los suspicaces adolescentes era un signo de la falta de sensibilidad social que se demostraba frente a las crisis. No 
extraña entonces que el confundido presidente Sebastián Piñera haya usado la traumática retórica de la "guerra" para referirse al conflicto que tenía ante sus narices. Ello no sólo parece confirmar que, en términos políticos, los defensores de una política de sesgo económico solo son astutos y previsores si en la otra mano tienen la garantía y la escolta de la fuerza militarizada, sino que revela la axiomática y la racionalidad de la democracia como dispositivo bélico-político (Arancibia 2018).

Recuérdese que, al inicio del estallido social no hubo ningún intento por establecer mesas de diálogo o de buscar salidas que apelaran a la escucha y a la comprensión de la pugna, sino que la respuesta fue clara y rotunda: «Estamos en guerra». La supuesta lucidez directiva de los expertos daba paso al berrinche cuando se les exigía razones y fundamentos consistentes. Es en ese momento cuando los militares entraron en acción para contribuir a la dirección del país. La complicidad del binomio Chicago boys-Pinochet estuvo más presente que nunca en la gestión de la crisis política ${ }^{3}$.

Por otro lado, hasta ahora, la gobernabilidad en Chile parecía consistir en la indolencia ante lo que padecían otros. De este modo, los daños y padecimientos de las regiones resultaban invisibilizados ante lo que ocurría en Santiago, la capital. Pero en este caso, dicho centralismo tuvo un efecto inesperado: la gente de Concepción, Valparaíso, Iquique, Valdivia, Quintero y Petorca, entre muchas otras localidades, tuvo, cada cual a su manera, la experiencia de una política deficiente que se materializa en cuestiones cotidianas: endeudamiento, medio ambiente, transporte y vivienda. Por ello sintonizaron y se sumaron a lo que en ese momento ocurría en Santiago. Finalmente, el llamado estallido social no sería entonces una sorpresa, era cosa de atención y de tiempo. El funcionamiento de la democracia y su permanente recurso a su mitologema permiten comprender el sentido y la potencia de la revuelta del octubre chileno.

\section{Conclusiones}

La democracia es un régimen mítico sobrevalorado si se atiende a la consecución efectiva de sus promesas fundacionales y legitimadoras. En el caso chileno, el mito democrático ha operado durante treinta años, ejerciendo su efecto de sacralización de la democracia. Un peritaje de política comparada a la experiencia democrática chilena exigiría examinar la brecha que existe entre sus enunciados y su operación efectiva. Es preciso - como expresan Mouffe o Rancière- exigir a los conceptos y principios democráticos que se verifiquen en su eficacia práctica.

Precisamente aquella brecha generada y administrada durante treinta años es lo que produce y desencadena el colapso democrático. Lo ocurrido en Chile durante octubre a

\footnotetext{
${ }^{3}$ La relación entre democracia, capital y guerra ha sido lúcidamente atendida por Lazzarato $(2019,18-91)$, lo que podría contribuir a este punto.
} 
diciembre de 2019 expresa la impugnación del «mitologema democrático». En efecto, durante 2020 — con Estado de Excepción mediante-se ha intentado restaurar la promesa y el mito de la democracia, operando como dispositivo para la preservación del orden social fundado bajo la égida de la dictadura. De la mano del sintagma de la transición, la democracia se ha vertebrado como la continuación de facto del orden social diseñado en dictadura. En ese sentido, la revuelta chilena de octubre parece concentrar el descontento hacia una serie de principios y condiciones forjadas durante décadas - querella que desde luego desborda ampliamente la coyuntura específica dispuesta por el gobierno de turno-. Octubre no es, entonces, un alzamiento sólo contra un gobierno, sino la puesta en cuestión de todo un sistema político, económico, social y cultural que acusó su quiebre y agotamiento.

Resulta evidente que la democracia chilena durante treinta años ha conservado una estrecha complicidad congénita y estructural con el modelo neoliberal (Harvey 2007; Klein 2007), el que finalmente ha incubado el descontento, el malestar y la rabia social. Por ello, resulta imprescindible interrogar y re-pensar la relación orgánica que existe entre democracia y capital. A nuestro entender, el capital es tan sólo un modo finito de la metafísica, y, a su vez, la democracia es un modo finito del capital (Arancibia 2019). Esto significa que — tal como sostenía Hayek (2008)—, según sea su necesidad, el capital puede agenciar o adoptar la forma jurídica de la democracia, pero también puede suspenderla, prescindir de ella y servirse de otras formas. Esto implica que la democracia es tan sólo un modo finito de ese otro modo finito. Ambos se encuentran actualmente en crisis. Como señalamos en la introducción, una amplia literatura ha elaborado esta crítica.

De esta manera, pensar el alzamiento de octubre implica pensarlo de modo situado en un plexo de relaciones amplias y complejas, sin reducirlo a un hecho aislado. De allí que examinar acuciosamente la experiencia democrática, implicaría atender también a su relación orgánica con el desarrollo y crisis del sistema capitalista mundial. Poner de manifiesto algunos aspectos específicos de este vínculo de la democracia chilena ha sido el propósito de este trabajo.

En coherencia con todo lo anterior, podríamos derivar dos líneas interrogativas en torno al «mitologema democrático»:

a) o bien lo que existe y ha existido en Chile los últimos treinta años sencillamente no es democracia, pues niega en la práctica lo que promete en el discurso (justicia, igualdad, dignidad, libertad). Cuestión que nos obligaría a pensar y crear - "ahora sí"一, una genuina y verdadera democracia (Abensour 1998) o bien b) —dado el vínculo orgánico entre democracia y capital-, en Chile efectivamente ha existido democracia real, y esto es todo cuanto ella puede. De modo que no habría que esperar ni exigir más de lo que ella es: un mitologema político como dispositivo de reproducción del patrón de acumu- 
lación del capital. Cuestión que reconduce a pensar que, en torno a la axiología política declarada, la democracia se muestra impotente e incompetente, de modo que habría que imaginar-pensar otra figuración política, más allá del «mitologema democrático».

Ante este dilema, particularmente nos inclinamos a pensar lo segundo, precisamente porque la democracia ha estado ya durante siglos orgánica y materialmente comprometida con las relaciones de dominación y vejamen contra la vida (Arancibia 2016b). Precisamente, en advertencia de aquello, es preciso preguntarnos “¿quién es y quién ha sido el sujeto de esta democracia?" (Yuing 2020). Ante aquella pregunta nos hacemos sensibles a la argumentación que nos comparte Wendy Brown, pulsando por concebir otro agenciamiento político:

Es esta figura del sujeto que sigue brindando a la democracia una legitimidad indisputable. Pero, al mismo tiempo, el rostro blanco, masculino y colonial de este sujeto ha permitido y perpetuado las jerarquías, las exclusiones y la violencia que marcaron la democracia en toda su existencia moderna. Por lo tanto, existe una no-libertad evidente y quizá necesaria en el corazón mismo de la democracia. Ello sugiere que, si el sueño imperial de hacer de todos los seres humanos libres se materializara, no asumiría la forma de la democracia (Brown 2010, 61).

Preguntamos entonces ¿cuál es el semblante de aquel personaje que ha sido el sujeto, conductor y tributario hegemónico de estos procesos democráticos? Si antes hemos advertido el vínculo orgánico entre democracia y capital, cabría también interrogarnos por el carácter de clase que ha tenido desde su gestación la democracia chilena. Nos parece que, pese a las permanentes transformaciones y adaptaciones declaradas desde la transición -incluyendo las últimas concesiones de salvataje del modelo-, la democracia no ha logrado ser encarnada por aquellos sujetos y sujetas cuyo entusiasmo y potencia ciudadana está a la base de la revuelta de octubre, y tampoco por los amplios sectores de la sociedad que libraron la lucha contra la dictadura. A pesar de su retórica inclusiva, emancipatoria y filantrópica, finalmente la democracia terminó siendo un modelo de desarrollo y enriquecimiento para el gran capital, las élites y raleas privilegiadas de una sociedad estructuralmente injusta y desigual. Ahí radica, en buena parte, los asomos de desconfianza, descrédito y desencanto - cuando no el abierto rechazo-, frente a los hitos oficializados por las mismas élites y castas de la institucionalidad política, como el acuerdo por la paz y la redacción de una nueva constitución.

Ante este cuadro, lícito y razonable se torna volver a preguntar ¿Quién es el sujeto que conduce, hegemoniza y protagoniza estos procesos de re-fundación democrática? ¿Qué tan efectivos y reales son los procedimientos de participación ciudadana a través de los cuales se redactará la nueva constitución? ¿Qué tan sustantivas y profundas son las transformaciones reales y concretas que este nuevo mitologema permitirá? ¿Qué tan posible resulta transformar los axiomas económicos y políticos de la judicatura democrático 
neoliberal, si ellos fueron instaurados y defendidos a sangre y fuego? ¿Qué posibilidades reales tiene la ciudadanía de darse su propia constitución en un escenario donde claramente las mismas castas políticas que han gobernado al servicio de los grandes poderes económicos vuelven a tomar el control obturando y asfixiando los espacios supuestamente democráticos? Finalmente preguntamos ¿y si este estratagema jurídico-político de legitimación de las élites gobernantes fracasara, qué otros posibles escenarios y vías de transformación política pudieran suscitarse? Estos problemas e interrogantes deberán examinarse con la evidencia de los hechos y los resultados. Los dados están echados, el mito democrático ha vuelto a trabajar.

\section{Agradecimientos}

Este artículo es parte del proyecto Fondecyt iniciación n¹1190173 "Estudio de la categoría de «stásis» en la tragedia y democracia griega. Hacia una genealogía trágico-política de la democracia", a cargo de Juan Pablo Arancibia Carrizo y del proyecto Fondecyt iniciación $\mathrm{n}^{\circ} 11180085$ "Biopolítica y racionalidad gubernamental: elementos para una renovación de los aportes de Foucault a la educación”, a cargo de Tuillang Yuing Alfaro.

\section{Referencias bibliográficas}

Abélès, Marc (2008). Política de la supervivencia. Buenos Aires: Eudeba.

Abensour, Miguel (1998). La democracia contra el Estado. Buenos Aires: Ediciones Colihue.

Agamben, Giorgio (2004). Estado de Excepción. Buenos Aires: Ediciones Adriana Hidalgo.

Anderson, C. y Y. V. Tverdova (2003). Corruption, Political Allegiances, and Attitudes Toward Government in Contemporary Democracies. American Journal of Political Science, 47(1), 91-109.

Arancibia, J.P. (2006). De la biopolítica y el dispositivo del tribunal. De la policía y el tribunal. En M. E. Tijoux y I. Trujillo (eds.), Foucault fuera de sí: deseo, historia, subjetividad (pp.105120). Santiago: Editorial Universidad Arcis.

Arancibia, J.P. (2010). Biopolítica, liberalismo y muerte. En I. Cassigoli (ed.), Biopolíticas del Sur (pp. 337-355). Santiago: Editorial Arcis.

Arancibia, J.P. (2011). El mito de la democracia: apuntes filosófico-políticos sobre el orden demoliberal en tiempos de bicentenario. En Carlos Ossa (ed.), Escrituras del Malestar: Chile del Bicentenario (pp. 171-193). Santiago: Ediciones Universidad de Chile.

Arancibia, J.P. (2016a). Mitologemas de lo político: democracia y poder constituyente. Revista Anales de la Universidad de Chile, 10, 127-143. https://doi.org/10.5354/07178883.2016.43146 
Arancibia, J.P. (2016b). La obliteración de la política: democracia y racionalidad de la excepción. En J.P. Arancibia y C. Salinas (eds.), Comunicación Política y Democracia en América Latina (pp. 201-214). Barcelona: Ediciones Gedisa-Ciespal.

Arancibia, J.P. (2018). Comunicación y democracia: conflictividad democrática y racionalidad de excepción. En H. Vera y J.P. Arancibia (eds), Información, Democracia y cibersociedad: una mirada desde Chile (pp. 163-188). Santiago: Centro de Estudios de Actualidad Nacional. Escuela de Periodismo. Universidad de Santiago de Chile.

Arancibia, J.P. (2019). Gubernamentalidad demoliberal: la democracia como dispositivo de guerra (ponencia). En J. Arancibia (coordinador), Excepción y guerra como principio planetario de gobierno. VII Coloquio Latinoamericano de Biopolítica. Santiago de Chile.

Arancibia, J. P., Yuing, T. (2019). Racionalidad comunicativa de la excepción. Editorial. Re-Presentaciones, Investigación en Comunicación, 12, 1-5. https://doi.org/10.35588/rp. v0i12.4322

Arendt, Hannah (1998). Orígenes del totalitarismo. España: Editorial Taurus.

Atria, Fernando (2013). Neoliberalismo con rostro humano. Santiago: LOM.

Badiou, A. (2010). El emblema democrático. En G. Agamben et al., Democracia, ¿en qué estado? (pp. 15-23). Buenos Aires: Prometeo.

Bobbio, Norberto (2003). El futuro de la democracia. México: Fondo de Cultura Económica.

Bringel, B., Pleyers, G. (2017). Protesta e indignación global. Los movimientos sociales en el nuevo orden mundial. Buenos Aires: CLACSO.

Brossat, Alain (2008). La democracia inmunitaria. Santiago: Editorial Palinodia.

Brown, Wendy (2010). Hoy en día, somos todos demócratas. En G. Agamben et al., Democracia, ¿en qué estado? (pp. 53-65). Buenos Aires: Prometeo.

Covarrubias, I. (2005). La globalización de la corrupción. Un efecto perverso de las transformaciones recientes en la política y la democracia. Bajo el Volcán, 5(9), 13-39.

Eco, Umberto (2000). Tratado de semiótica general. Barcelona: Lumen.

Esposito, Roberto (1996). Confines de lo político. Madrid: Editorial Trotta.

Foucault, Michel (2006). Nacimiento de la Biopolítica. Curso en el Collège de France 19771978. Buenos Aires: Fondo de Cultura Económica.

Habermas, Jürgen (1999). La inclusión del otro. Estudios de teoría política. Barcelona: Ediciones Paidós.

Hardt, M., Negri, T. (2002). Imperio. Buenos Aires: Paidós.

Harvey, David (2007). Breve historia del neoliberalismo. Madrid: Akal.

Hayek, F. (2008). Camino de servidumbre. Madrid: Unión Editorial. 
Jaramillo Gabanzo, N. J. (2010). Clase dirigente y corrupción política: 1837-1839 en la Nueva Granada. [Tesis de Maestría]. Bogotá: Universidad Nacional de Colombia. Facultad de Ciencias Humanas, Bogotá, Colombia.

Klein, Naomi (2007). La doctrina del shock. El auge del capitalismo del desastre. Buenos Aires: Paidós.

Lazzarato, Maurizio (2019). Le capital déteste tout le monde. Fascisme ou révolution. París: Éditions Amsterdam.

Lechner, Norbert (1988). Los patios interiores de la democracia. Subjetividad y política. Santiago: FLACSO.

Lefort, Claude (1990). La invención democrática. Buenos Aires: Nueva Visión.

Levitsky, S., Ziblatt, D. (2018). How Democracies Die. New York: Crown Publishing.

Linz, J. (1988). Legitimacy of Democracy and the Socioeconomic System. En Mattei Dogan (ed.), Comparing Pluralist Democracies (pp. 64-112). Boulder: Westview Press.

Macpherson, Crawford (2003). La democracia liberal y su época. Madrid: Alianza Editorial.

Mayol, Alberto (2012). El derrumbe del modelo. La crisis de la economía de mercado en el Chile contemporáneo. Santiago: LOM.

Mouffe, Chantal (1999). El retorno de lo político. Barcelona: Editorial Paidós.

Moulian, Tomás (1997). Chile actual: anatomía de un mito. Santiago: LOM.

Mounk, Yascha (2018). The People vs Democracy. Massachusetts: Harvard University Press.

Nancy, Jean-Luc (2001). La comunidad desobrada. Madrid: Arena Libros Editores.

Nancy, Jean-Luc (2009). La verdad de la democracia. Buenos Aires: Amorrortu.

Pinochet, Augusto (1977). Nueva institucionalidad en Chile. Discursos de S.E. el Presidente de la República General de Ejército D. Augusto Pinochet Ugarte. [Santiago: Editor no identificado].

Ramírez, C., Yáñez-Urbina, C., Salinas, I. (2019). Chile, la democracia se acabó: crisis institucional en el 18-O. Re-Presentaciones, Investigación en Comunicación, 12, 6-28. https://doi. org/10.35588/rp.v0i12.4317

Rancière, Jacques (1994). En los bordes de lo político. Santiago: Editorial Universitaria.

Rosanvallon, Pierre (2007). La contrademocracia. La política en la era de la desconfianza. Buenos Aires: Editorial Manantial.

Rosanvallon, Pierre (2009). La legitimidad democrática. Buenos Aires: Editorial Manantial.

Rosanvallon, Pierre (2011). La sociedad de los iguales. Madrid: RBA ediciones.

Ruiz Schneider, Carlos (1993). Seis ensayos sobre teoría de la democracia. Santiago: Ediciones Universidad Andrés Bello.

Runciman, David (2018). How Democracy Ends. London: Profile Books Ltd. 
Salazar, G., Pinto, J. (1999). Historia contemporánea de Chile, vol. 1. Estado, legitimidad y ciudadanía. Santiago: LOM.

Thayer, Willy (1996). La crisis no moderna de la universidad moderna. Santiago: Cuarto Propio.

Tocqueville, Alexis (1984). La democracia en América, vol. II. Madrid: Editorial Sarpe.

Todorov, Tzvetan (2017). Los enemigos íntimos de la democracia. Barcelona: Galaxia Gutenberg.

Touraine, Alain (2006). ¿Qué es la democracia? México: Fondo de Cultura Económica.

Traverso, Enzo (2001). El totalitarismo. Historia de un debate. Buenos Aires: Editorial Eudeba.

Yuing, T. (octubre de 2020). ¿Qué pueden las masas? Notas sobre la noción de Hoi Polloi y sus desafíos para la democracia (ponencia). En J. Arancibia (Coordinador), Stásis, tragedia y democracia griega. Seminario de Investigación Fondecyt, Universidad de Santiago de Chile. Santiago de Chile.

Waissbluth, Mario (2010). Se acabó el recreo. Santiago: Debate.

Wolin, Sheldon (2008). Democracia S.A. La democracia dirigida y el fantasma del totalitarismo invertido. Buenos Aires: Editorial Katz. 
